Prepared for the U.S. Department of Energy

under Contract DE-AC05-76RL01830

\title{
Forming Limits of Weld Metal in Aluminum Alloys and Advanced High-Strength Steels
}
EV Stephens
GJ Grant
MT Smith
RW Davies

October 2010

\section{Pacific Northwest}

NATIONAL LABORATORY

Proudly Operated by Battelle Since 1965 


\title{
DISCLAIMER
}

This report was prepared as an account of work sponsored by an agency of the United States Government. Neither the United States Government nor any agency thereof, nor Battelle Memorial Institute, nor any of their employees, makes any warranty, express or implied, or assumes any legal liability or responsibility for the accuracy, completeness, or usefulness of any information, apparatus, product, or process disclosed, or represents that its use would not infringe privately owned rights. Reference herein to any specific commercial product, process, or service by trade name, trademark, manufacturer, or otherwise does not necessarily constitute or imply its endorsement, recommendation, or favoring by the United States Government or any agency thereof, or Battelle Memorial Institute. The views and opinions of authors expressed herein do not necessarily state or reflect those of the United States Government or any agency thereof.

\author{
PACIFIC NORTHWEST NATIONAL LABORATORY \\ operated by \\ BATTELLE \\ for the \\ UNITED STATES DEPARTMENT OF ENERGY \\ under Contract DE-AC05-76RL01830
}

Printed in the United States of America
Available to DOE and DOE contractors from the Office of Scientific and Technical Information,
P.O. Box 62, Oak Ridge, TN 37831-0062;
ph: (865) 576-8401
fax: $(865)$ 576-5728
email: reports@adonis.osti.gov

\begin{abstract}
Available to the public from the National Technical Information Service, U.S. Department of Commerce, 5285 Port Royal Rd., Springfield, VA 22161 ph: (800) 553-6847 fax: $(703) 605-6900$ email: orders@ntis.fedworld.gov online ordering: http://www.ntis.gov/ordering.htm
\end{abstract}

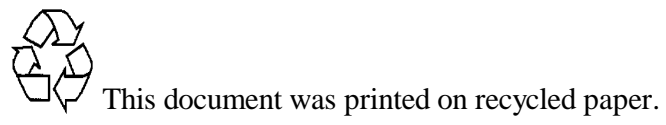




\section{Forming Limits of Weld Metal in Aluminum Alloys and Advanced High-Strength Steels}

EV Stephens

MT Smith

October 2010
GJ Grant

RW Davies
Prepared for the U.S. Department of Energy

under Contract DE-AC05-76RL01830

Pacific Northwest National Laboratory

Richland, Washington 99352 


\section{Executive Summary}

The automotive industry is continually working toward reducing vehicle emissions and fuel consumption. A substantial portion of these efforts is focused on reducing overall vehicle weight. Tailor welded blank (TWB) and seam-welded tubing technology gives automotive producers the ability to selectively vary body panel thickness to ultimately reduce vehicle cost, weight, and fuel consumption. Figure 1 below illustrates the importance of weld formability to tailor welded blanks and tube hydroforming; as well as the state of different materials systems that is used and will be used in future vehicles.

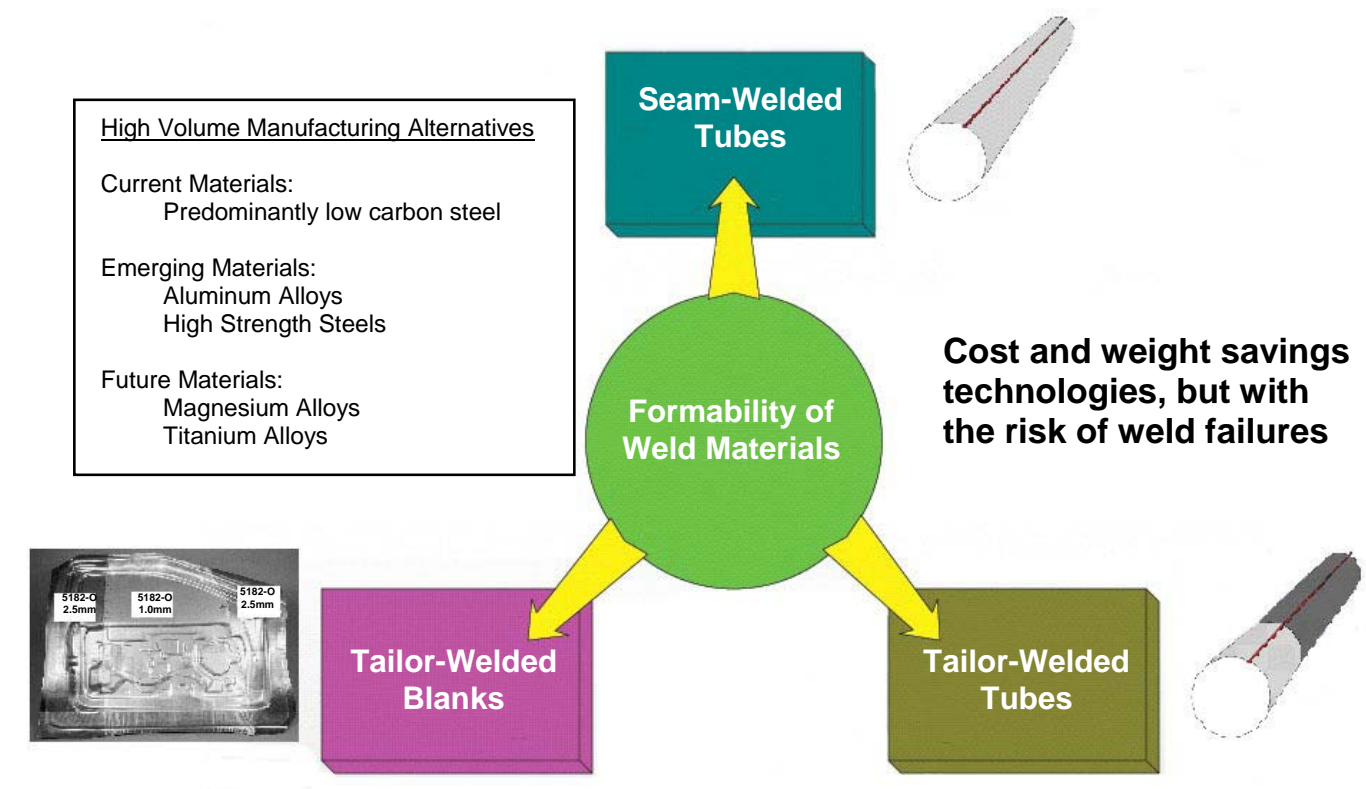

Figure 1. A schematic of the formability of weld materials.

This project developed and validated numerical methods that describe the forming limits of weld materials in aluminum alloys and high-strength steels through a combination of experimental and deformation modeling analysis. The deformation of weld materials and their limits of formability are important aspects to both tailor welded blank and hydroforming technology. The conventional lowcarbon steels used in automotive applications are easily fusion welded using conventional technology, and suffer no appreciable strength degradation near the weld. Aluminum alloys are more difficult to weld than low-carbon steels due to high conductivity and reflectivity, and low molten viscosity. Aluminum also has a high propensity for porosity to form during fusion welding, as well as hot cracking and heataffected zone (HAZ) related issues in heat-treatable aluminum alloys. Many of the high-strength steel alloys that are finding increasing application in the automotive industry suffer from degradation of strength in the HAZ. Furthermore, nearly all fusion welds suffer from irregular geometries and elevated levels of surface roughness compared to the parent materials - which also influence formability and component performance.

This work characterizes the mechanical properties of AA5182-O welds and DP600 laser welded TWBs near and in the weld, as well as their limits of formability. The approach uses simple uniaxial experiments to measure the variability in the forming limits of the weld region, and uses a theoretical forming limit diagram calculation to establish a probabilistic distribution of weld region imperfection using an M-K method approach. The probabilistic distribution of imperfection is then used to establish the probability of failure of this DP600 TWB population at specific levels of plastic deformation. This 
probabilistic approach should allow a stamping process designer to understand the risk of part failure (or part failure rate) being assumed when designing a TWB stamping process.

The biaxial stretching performance of TWBs was investigated using Limiting Dome Height (LDH) experimental apparatus, as well as other methods. The LDH testing was used to evaluate and validate the uniaxial stretching data, and ultimately provide an independent method of validating the probabilistic methods dependent upon uniaxial data. The biaxial data was shown to require a three-quadrant FLD; where the formability of the TWB must be treated distinctly different depending whether the primary axis of loading is either transverse or longitudinal to the weld-direction orientation.

The overall results of this research show that increasing sophisticated methods of characterizing the probabilistic nature work the forming limits of weld material are necessary as the materials have increasing sophistic thermomechanical processing (TMP) and chemical composition to achieve highstrength and more weight reduction potential. The TMP used for producing highly attractive monolithic automotive parts requires increasing knowledge and process rigor as they are used for TWBs as well as welded and tailor welded tubes. However, the materials appear to be capable of being used in vehicle weight reducing as long as the developers and deployers of the technology understand how to address the probabilistic nature of the forming limits of weld materials. 


\section{Acknowledgements}

The Pacific Northwest National Laboratory is operated by Battelle Memorial Institute for the United States Department of Energy under Contract DE-AC05-76RL01830. The authors would like to acknowledge Dr. Joseph Carpenter formerly of the Department of Energy Office of Vehicle Technologies Program for supporting this work. The authors would also like to acknowledge United States Steel Corporation and Alcoa for providing materials and collaborating on this research. 


\section{Figures}

Figure 1. A schematic of the formability of weld materials

Figure 2. The strain-rate results from the DIC analysis of a longitudinal LW DP600 specimen at four different levels of deformation during uniaxial testing.....

Figure 3. Uniaxial specimen design for longitudinal and transverse specimens. Measurements in millimeters.

Figure 4. The stress-strain curves of the parent materials and weld material of the 5182-6111 TWB

Figure 5. An illustration of the DIC strain data just prior to fracture on a LW DP600 limited dome-height test

Figure 6. Photo representative of failure observed in the thin sheet of full dome limited dome height tests of the 5182 TWB welded alloy

Figure 7. Photo representive of failures observed in the lock bead region of 4-inch and 1.5-inch LDH specimens

Figure 8. An illustration of the DIC strain data just prior to fracture on a 4-inch width 5182 welded dome height specimen. Fracture occurred in the red region

Figure 9. Schematic illustration of the M-K model extended to include weld thickness differences and two orientations of imperfection in the weld

Figure 10. DP600 TWB FLD developed utilizing the industrially relevant procedure

Figure 11. Illustration of the LDH (limiting dome height) results of biaxial experiments in near biaxial stretching and the applied loading during these experiments

Figure 12. DP600 TWB FLD developed utilizing the industrially relevant procedure compared to a set of biaxial stretching result of the same weld population. 


\section{Introduction}

The deformation of weld materials and their limits of formability are important aspects to both tailorwelded blanks (TWB) and hydroforming technologies. The conventional low-carbon steels used in automotive applications are easily fusion-welded using conventional technologies and suffer no appreciable strength degradation near the weld. Aluminum alloys are more difficult to weld than lowcarbon steels due to high conductivity and reflectivity as well as low-molten viscosity. Aluminum also has a high propensity for porosity to form during fusion welding as well as hot cracking and heat-affected zone (HAZ)-related issues in heat-treatable aluminum alloys. Many of the high-strength steel alloys that are finding increased application in the automotive industry suffer from degradation of strength in the HAZ. Further, nearly all fusion welds suffer from irregular geometries and elevated levels of surface roughness compared to the parent materials, which also influence formability and component performance.

In this project, research was performed to develop test methods and experimental results to enable the widespread deployment of weight- optimized TWB and tube hydroforming and to avoid weld failures during production. The goal of this project is to develop a procedure for industry to use by characterizing the variability of these materials to reduce the risk assumed while deploying this weight-saving technology to enable greater commercialization. A standard procedure for weld material evaluation coupled with a numerical approach for establishing weld region forming limits was generated to describe the forming limit operating envelope of TWB materials. Research focused on developing the generalized numerical method to predict forming limits in weld materials and verifying deformation and forming limit predictions. The approach relied on developing standardized test methods for weld material populations to establish a statistical description of material imperfection and mechanical properties in their weld region and developing statistically based forming limit diagrams (FLD) that predict material failure in the weld region.

A number of candidate weld methods were examined in combination with selected aluminum alloys and

high-strength steels. The principal materials of interest were aluminum alloys AA5182 and AA6061 and DP600 steel. The selection of sheet materials and welding methods were coordinated with participating original equipment manufacturers (OEMs) and are representative of high-volume commercially viable materials and processing technologies.

The results of this work allow the evaluation and development of candidate weld processes and the interaction between materials and weld parameters and will enable high-volume, robust deployment of TWBs and seam-and tailor-welded tubes in emerging materials. 


\section{Experimental Characterization}

Experimental characterization focused on incorporating digital image correlation as a strain-evaluation method, uniaxial testing with a simple geometric specimen design, and biaxial testing. The TWB material combinations evaluated were laser-welded (LW) DP600 1.5mm to DP600 1mm steel, friction stir welded (FSW) AA5182-O 2mm to AA5182-O 1mm, and FSW AA5182-O 2mm to AA6111-T4 1.5mm with greater emphasis on the DP600 and AA5182-6111 welded alloys.

\section{Strain Characterization Utilizing Digital Image Correlation}

Digital image correlation (DIC), or speckled pattern interferometry, has been applied for use with uniaxial tests and biaxial limited dome-height formability tests. DIC is a data-analysis method which uses an algorithm to analyze digital image data taken when a sample is subjected to mechanical strain.

Displacement and strain are measured. This technique uses white-light speckle correlation, where two similarly speckled images captured by a video camera represent the state of the object before and after deformation. Consecutive images are captured during testing and the image correlation will register a change in surface characteristics as the specimen is affected by stresses imposed upon it. The actual object movement is measured and the Lagrangian strain tensor is available at every point on the surface.

This technique allowed us to further understand strain localization in a non-homogenous gage such as a weld. We were able to track strain localization and strain variation of the welded parts during forming. For example, Figure 2 illustrates the strain rate results from the DIC analysis during uniaxial testing of a LW DP600 longitudinal specimen. Four levels of deformation are shown. The faint line in the illustrations is the weld. Localization occurs when the local strain rate is much greater than the overall specimen strain rate. In this specimen, as in all the other longitudinal DP 600 specimens, we observe the strain rate localizing in the weld just prior to failure.
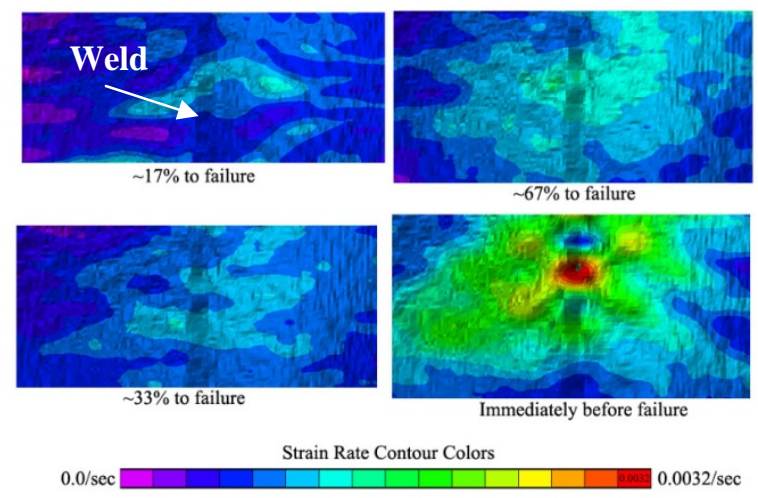

Figure 2. The strain-rate results from the DIC analysis of a longitudinal LW DP600 specimen at four different levels of deformation during uniaxial testing.

\section{Uniaxial Experimental Testing}

Uniaxial tests were performed on rectangular specimens that were designed with the weld oriented either longitudinal or transverse to the tensile axis as shown in Figure 3. Thirty longitudinal and thirty transverse specimens were made for each welded TWB material combination. All specimens were etched with square grids to determine the incipient necking condition utilizing optical strain grid analysis (a more conventional method) in addition to DIC. All tests were stopped after an 8\% drop in load. 


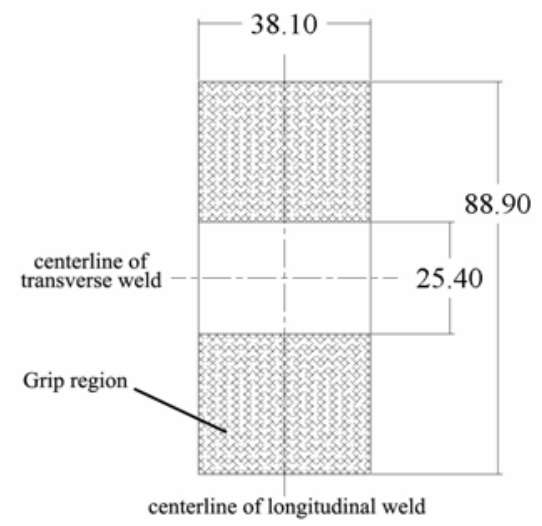

Figure 3. Uniaxial specimen design for longitudinal and transverse specimens. Measurements in millimeters.

All thirty uniaxial DP600 longitudinal specimens failed in the weld. All thirty of the transverse specimens failed in the thin sheet away from the weld and weld region (HAZ). Localization occurs in the weaker thin sheet. Failure is determined by the weld properties in the longitudinal DP600 welded specimens, where as failure is determined by the properties of the thin parent sheet material in the transverse specimens.

For the 5182-6111 friction-stir-welded alloys, all thirty longitudinal specimens failed in the weld and twenty-nine of the thirty transverse specimens failed in the HAZ of the thin sheet 6111 material. Miniature tensile tests performed on specimens removed from the weld and weld region indicated the weld material to be a strong, yet less ductile, material in comparison to the parent sheets (Figure 4) and weaker in the HAZ. A depression in strength was observed in the HAZ. In this welded-alloy combination, failure is determined by the weld properties in the longitudinal specimens, where as failure is determined by the HAZ of the thinner 6111 material in transverse specimens.

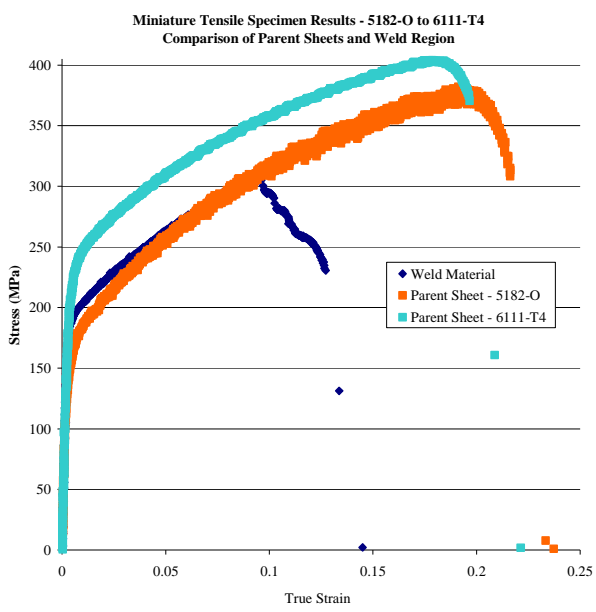

Figure 4. The stress-strain curves of the parent materials and weld material of the 5182-6111 TWB.

For the FSW 5182 welded alloys, twenty-nine of the thirty longitudinal specimens failed in the grip region and all thirty transverse specimens also failed in the grip region. Miniature tensile tests performed on specimens removed from the weld and weld region indicated the weld material to be just as ductile and 
strong as the parent sheet. Minimal mechanical property gradients across the weld and weld region were observed.

\section{Biaxial Experimental Testing}

Biaxial limited dome-height tests were performed on the DP600, 5182, and 5182-6111 welded alloys. Both full domes and 4-inch-wide domes were tested, with a minimum of five specimens tested for each condition. For the 5182 welded alloys, 1.5 inch wide domes in addition to both full domes and 4-inch wide domes were also tested. Smaller width domes were implemented to obtain uniaxial strain data since the smaller the width of the dome, the closer the behavior is to uniaxial. In addition, full dome tests were conducted on the parent sheet materials for all TWB combinations. Both optical strain grid analysis and DIC was used to evaluate the specimens. Figure 5 is an illustration of the DIC analysis for a full- dome DP600 welded specimen.

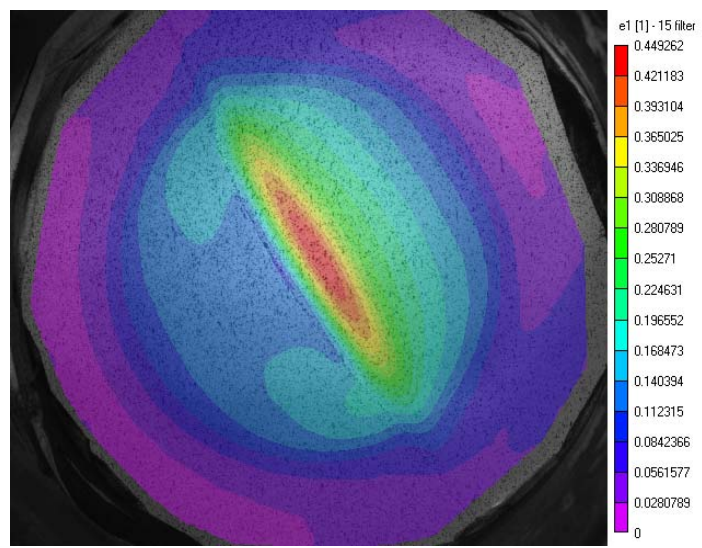

Figure 5. An illustration of the DIC strain data just prior to fracture on a LW DP600 limited dome-height test.

For the DP600 welded specimens, all full-dome biaxial tests failed in the thin sheet parallel to the weld. All 4-inch-width domes failed in the weld, transverse to the weld.

For the 5182-6111 welded specimens, all full-dome biaxial tests failed in the weld; however, two different failure modes were observed. The specimens either failed in the weld, longitudinal to the weld, or failed in the weld, transverse to the weld with the crack propagating into the thin sheet 6111 material. In the 4-inch-width dome tests, all specimens failed in the weld, transverse to the weld.

For the 5182 welded specimens, all full dome biaxial tests failed in the thin sheet (Fig. 6). Testing then continued with the 4-inch wide specimens; however, failures in the lock bead region of the thin sheet were observed when the same test conditions as in the full dome height tests were used. Figure 7 illustrates the failure observed. Failure in the lock bead is typically indicative of too large of a clamp load. When the clamp load was reduced, failures in the lock bead still occurred regardless of the pressure used. Even when excessive draw in took place. An acceptable clamp load was ultimately found, and much effort and care was put forth in specimen preparation and shimming of the specimen to reduce excessive failures in the lock bead.

Fourteen 4-inch width specimens were tested at the same test conditions, and six of the fourteen specimens failed in the weld, transverse to the weld. Failure in the lock bead prevented the other specimens from reaching full height. Figure 8 illustrates the DIC strain data for a 4-inch width specimen. 


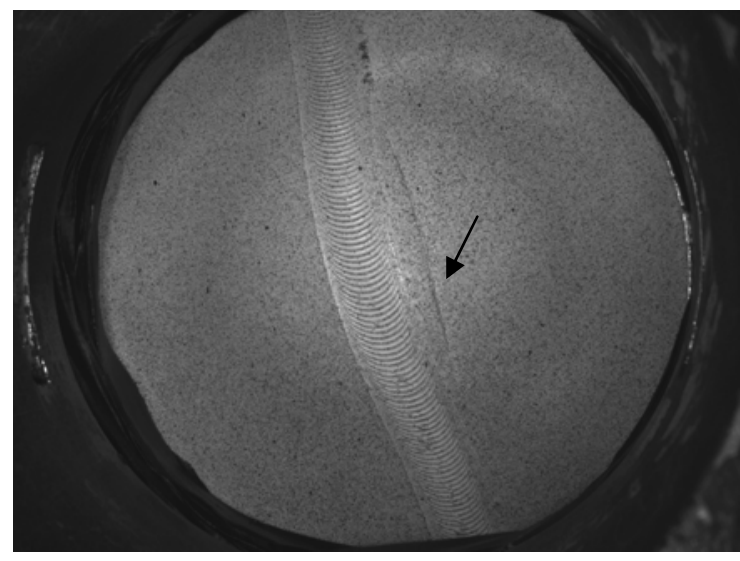

Figure 6. Photo representative of failure observed in the thin sheet of full dome limited dome height tests of the 5182 TWB welded alloy.

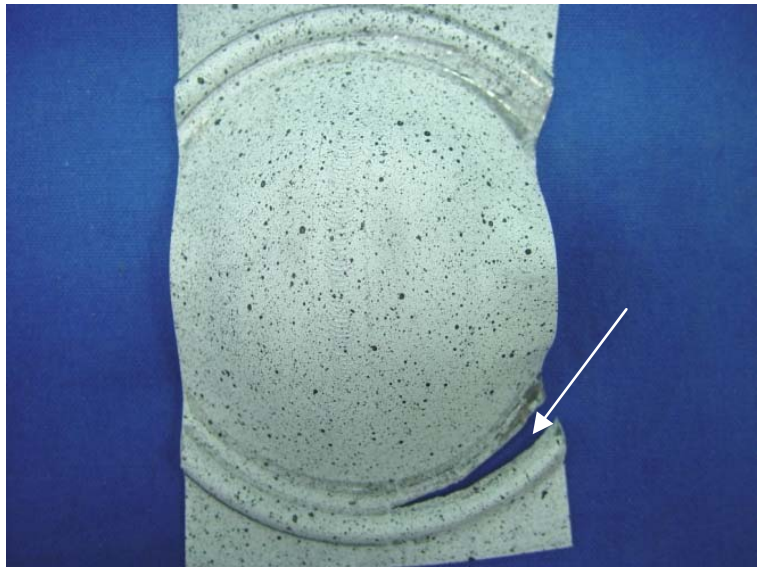

Figure 7. Photo representive of failures observed in the lock bead region of 4-inch and 1.5-inch LDH specimens.

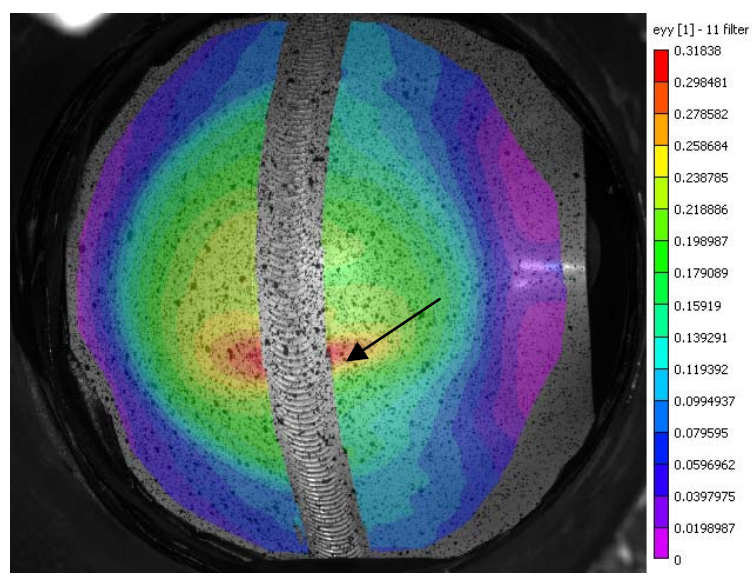

Figure 8. An illustration of the DIC strain data just prior to fracture on a 4-inch width 5182 welded dome height specimen. Fracture occurred in the red region. 
Limited dome height tests of the 1.5- inch width FSW 5812 specimens were not successful. All specimens tested failed in the lock bead region of the thin sheet. Failure still occurred in the lock bead region when a low clamp load was used that allowed excessive draw in. When a monolithic, $1 \mathrm{~mm}$ thick, 1.5 inch-width 5182 specimen was tested, failure was still observed in the lock bead region. Modifications to the lock bead radius may be needed to prohibit failure in the lock bead region. 


\section{M-K Method to Predict Formability}

The prediction of TWB formability in this work relies fundamentally upon the Marciniak-Kuczynski (MK) [1] method coupled to an experimentally-derived measure of weld material imperfection. The M-K method tracks development of plastic strains in the monolithic sheet and weld materials under applied external loading. The M-K method is predicated on the assumption that real materials possess imperfections (or geometric inhomegeneities) and that the strain evolution and eventual localization at the imperfection is the source of failure during metal forming.

Imperfection levels for a given tailor welded blank population were determined from the tensile tests performed in each of the directions longitudinal and transverse to the weld within the TWB. The level of imperfection $(f)$ that must exist in the specimens in order to describe the formability for each of the thirty specimens is determined using M-K methods. Given the localization strain from each test, and the variations in the localization strain, one can establish a statistically-based level of imperfection for each weld population in both the longitudinal and transverse direction. Figure 9 is a schematic of the M-K model.

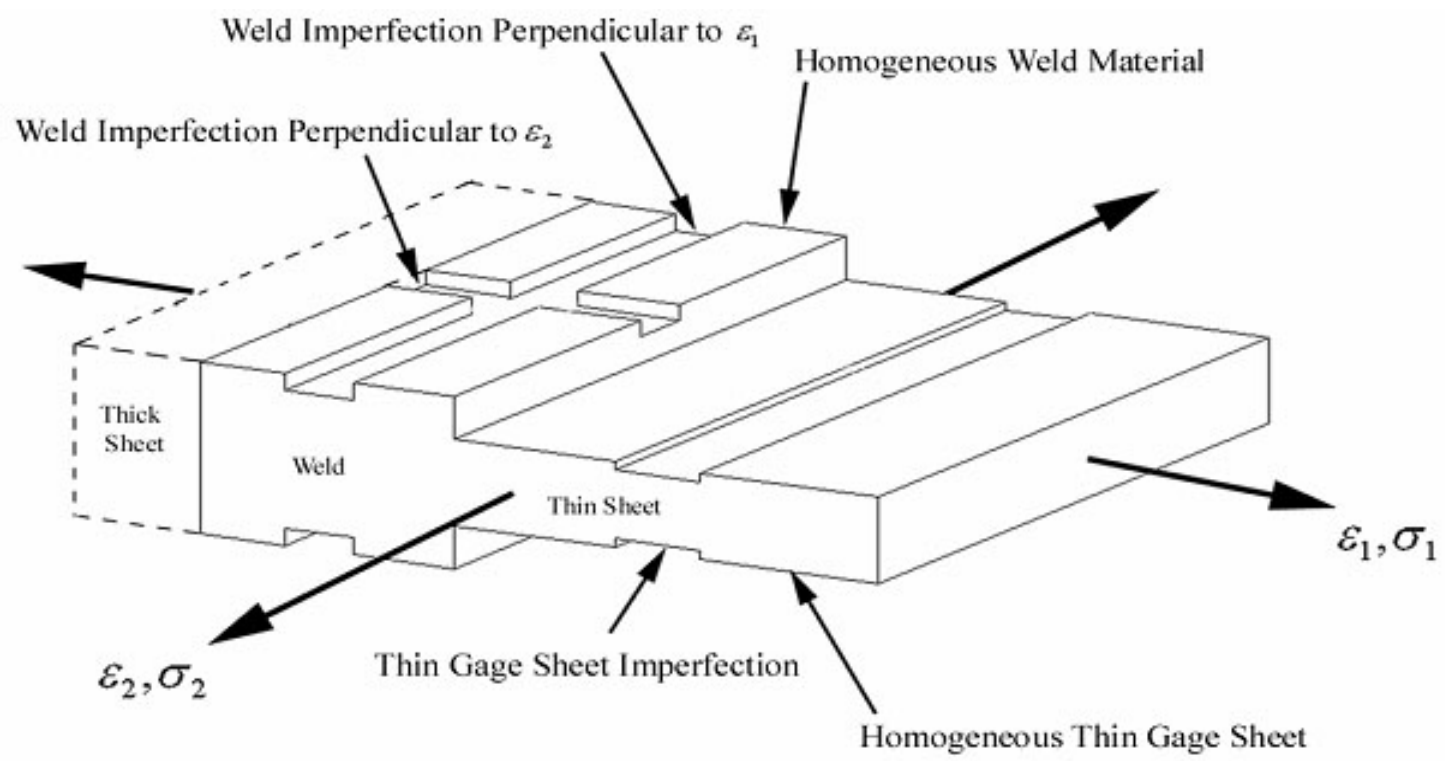

Figure 9. Schematic illustration of the M-K model extended to include weld thickness differences and two orientations of imperfection in the weld.

The Weibull probability distribution has proven to be the most suitable to describe the specimen imperfections, and the predicted FLD for the TWBs is generated using this function. Using this standard function permits an active selection of the level of risk that the practitioner assumes during manufacturing to develop safe forming limit diagrams for a given weld population. 


\section{General Procedure in Determining the FLD of Welded Alloys}

Currently, there is no industrial standard that describes the formability of TWBs that include the effects of the weld region. Again, the primary goal of this project is to develop a procedure for industry to use by characterizing the variability of these materials to reduce the risk assumed while deploying this weightsaving technology to enable greater commercialization. This project has generated a procedure to describe the forming limit operating envelope of TWB materials. The general procedure was first applied to DP600 welded alloys. Figure 9 depicts the DP600 TWB FLD generated from the 10-step process described below:

1. Establish the thin (or the weaker) sheet FLD and draw a three-quadrant FLD where longitudinal strain is the ordinate (y-axis) and the transverse strain is the abscissa (x-axis) for this material

2. Conduct approximately 30 longitudinal tensile tests and measure the "safe" level of strain in the thin sheet adjacent to the weld for each specimen

3. Calculate the statistical distribution for the level of imperfection for the longitudinal specimens

4. Conduct approximately 30 transverse tensile tests and measure the "safe" level of strain in the thin sheet adjacent to the weld for each specimen and verify that no weld related failures occurred

Note: Experimental results showed that in the transverse weld condition, there was no fracture in the weld or in the heat affected zone of the DP600 welded specimens. Localization occurred in the thin sheet, and fracture was determined by the properties of the $1 \mathrm{~mm}$ parent sheet material. Therefore, the $1 \mathrm{~mm}$ sheet FLD dictates TWB failure in transverse loading conditions.

5. Assume the acceptable failure rate for a given metal forming application (recommendation is 1 part per 1000)

6. Calculate the imperfection level for the longitudinal population that corresponds to the acceptable failure rate

7. Calculate the "safe" level of strain along the longitudinal tensile direction that corresponds to the acceptable failure rate (Locate Point 1 on diagram)

8. Calculate the strain path direction developing in the thin sheet when the weld is being loaded in plane strain longitudinal to the weld and place a point on the FLD that corresponds to the "safe"

longitudinal plane strain and the transverse strain in the thin sheet (Locate Point 3 on the diagram)

9. Connect Points 1 and 3 via a line

10. Draw a horizontal line from Point 3 horizontal to intersect the thin sheet FLD to the right of Point 3

In Figure 10, the safe FLD for this TWB population is defined as the condition where no more than 1 part per 1000 parts formed will fail under biaxial stretching. In practice, the working strain during forming should be limited such that it remains under the 1 part per 1000 forming limit and the thin sheet FLD in the transverse direction.

In order to validate this approach, a set of biaxial forming experiments were conducted with the identical TWB population. Figure 11 illustrates the LDH (limiting dome height) results of biaxial experiments in near biaxial stretching, and the shows the loading applied and lubrication used during these experiments. This set of tests compares the failure strain when sheet is loaded biaxially, and permits comparison of predicted and actual failure strains. Figure 12 compares this biaxial data to the predicted FLD for the given weld population. The biaxial data is on or near the $50 \%$ failure rate line, which would be expected given a small number of samples. 


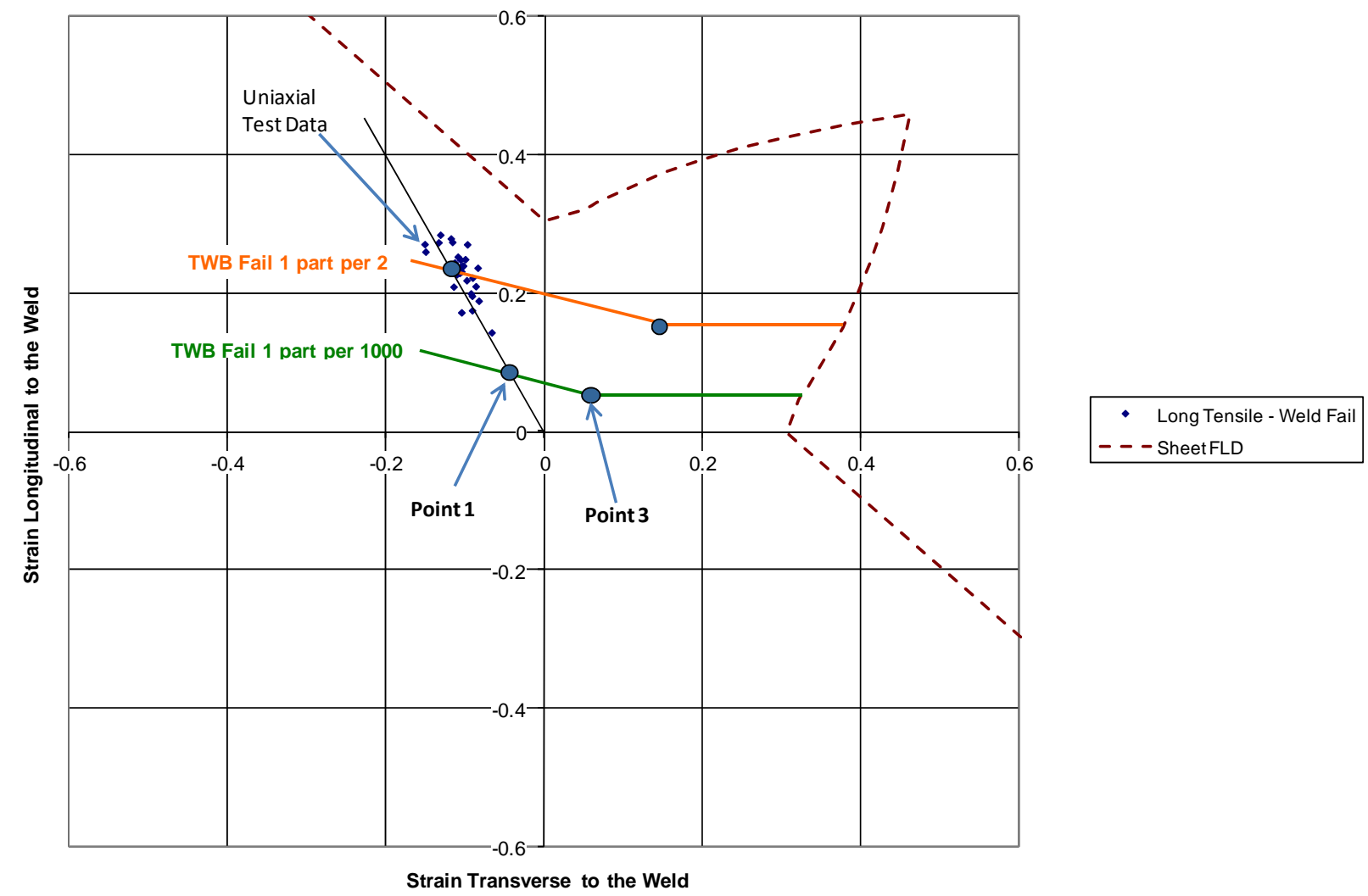

Figure 10. DP600 TWB FLD developed utilizing the industrially relevant procedure.

\section{Photos representative of the LW DP600 specimens after LDH testing. Fracture in the thin sheet observed in all specimens. Table below illustrates the loads and heights observed.}
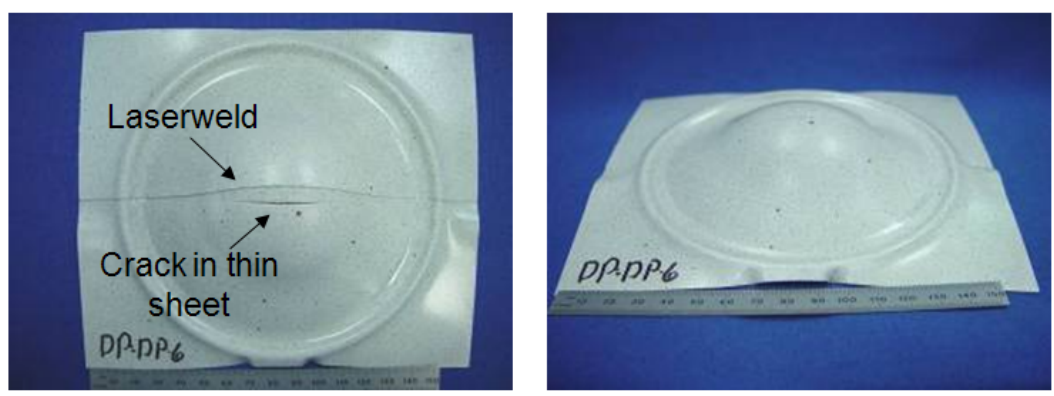

\begin{tabular}{lllcccc}
\hline Specimen ID & $\begin{array}{c}\text { Specimen } \\
\text { Thickness }\end{array}$ & Lubricant & $\begin{array}{c}\text { Clamp Test } \\
\text { Load (lb) }\end{array}$ & $\begin{array}{c}\text { Punch Test } \\
\text { Rate } \\
\text { (in./min) }\end{array}$ & $\begin{array}{c}\text { Max Load } \\
\text { Detected (Ib) }\end{array}$ & $\begin{array}{c}\text { Height At } \\
\text { Max Load } \\
\text { (in.) }\end{array}$ \\
\hline \hline & & & & & & \\
DP-DP-3 & $1.5 \mathrm{~mm}$ to $1 \mathrm{~mm}$ & Teflon & 38,000 & 0.05 & 20,824 & 1.05 \\
DP-DP-4 & $1.5 \mathrm{~mm}$ to $1 \mathrm{~mm}$ & Teflon & 38,000 & 0.05 & 20,915 & 1.06 \\
DP-DP-5 & $1.5 \mathrm{~mm}$ to $1 \mathrm{~mm}$ & Teflon & 38,000 & 0.05 & 19,736 & 1.03 \\
DP-DP-6 & $1.5 \mathrm{~mm}$ to $1 \mathrm{~mm}$ & Teflon & 38,000 & 0.05 & 19,453 & 1.01 \\
DP-DP-7 & $1.5 \mathrm{~mm}$ to $1 \mathrm{~mm}$ & Teflon & 38,000 & 0.05 & 18,920 & 0.98 \\
\hline
\end{tabular}

Figure 11. Illustration of the LDH (limiting dome height) results of biaxial experiments in near biaxial stretching and the applied loading during these experiments. 


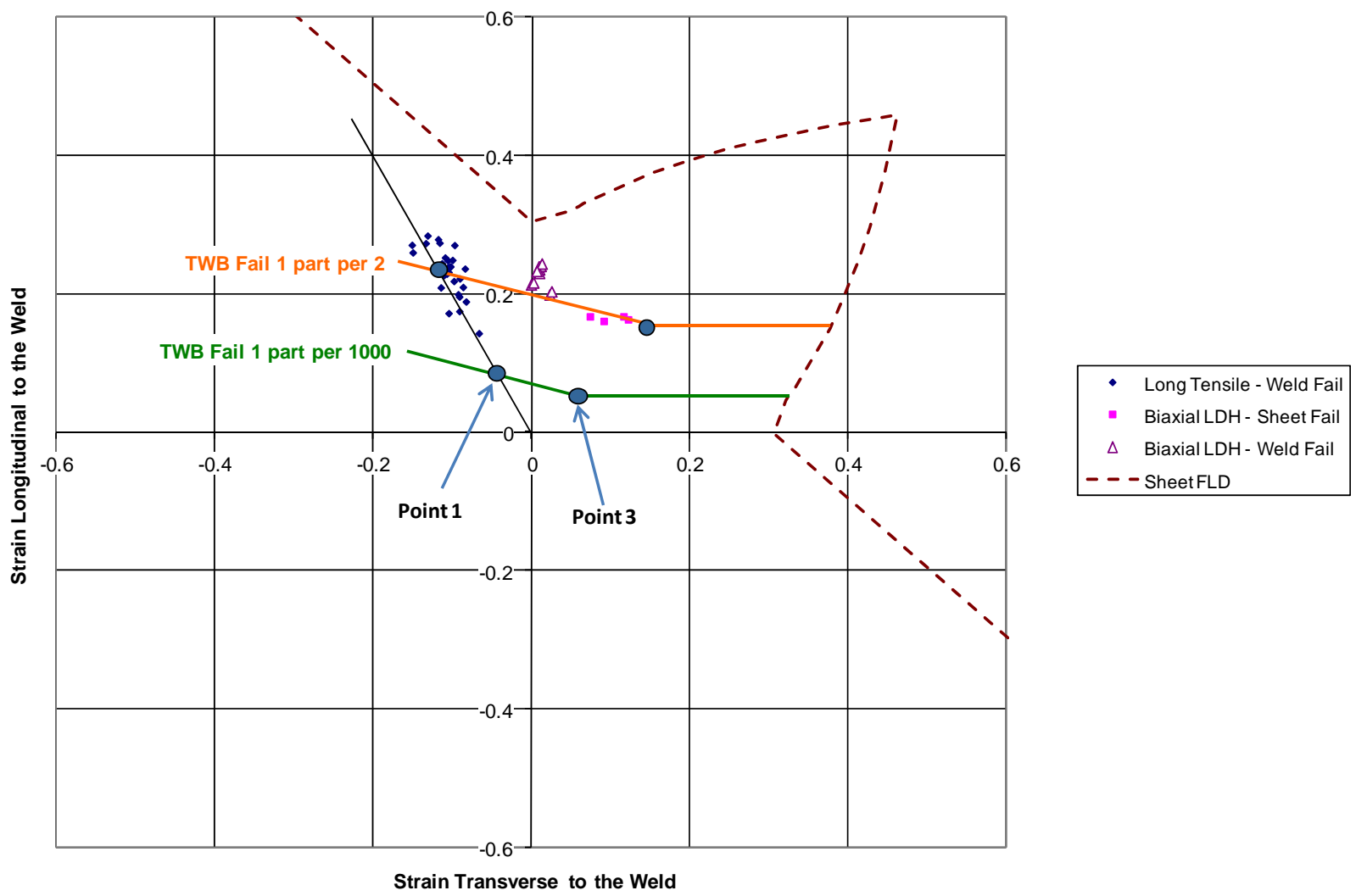

Figure 12. DP600 TWB FLD developed utilizing the industrially relevant procedure compared to a set of biaxial stretching result of the same weld population. 


\section{Conclusions}

This work characterizes the mechanical properties of DP600 laser welded TWBs $(1 \mathrm{~mm}-1.5 \mathrm{~mm})$ near and in the weld, as well as their limits of formability. The approach uses simple uniaxial experiments to measure the variability in the forming limits of the weld region, and uses a theoretical forming limit diagram calculation to establish a probabilistic distribution of weld region imperfection using an $\mathrm{M}-\mathrm{K}$ method approach. The probabilistic distribution of imperfection is then used to establish the probability of failure of this DP600 TWB population at specific levels of plastic deformation. This probabilistic approach should allow a stamping process designer to understand the risk of part failure (or part failure rate) being assumed when designing a TWB stamping process. From this investigation, the following conclusions were derived:

1. Forming of TWB's has the potential to simultaneously reduce the cost and weight of lightweight automotive structures.

2. Emerging materials (aluminum and AHSS) are generally more challenging to join and form.

3. This project has developed a standard approach for describing the forming limits that include the effects of the weld region, which predicts forming failure rates at quantitative levels of deformation.

4. The fundamental understanding of the forming behavior of the weld metal and TWB sheet materials allows the automotive user to determine the best design and applications for TWB deployment.

5. Using the test and analysis methods developed by this project the automotive user can determine the forming limits for the TWB application and the associated probable failure rates, and thus reduce the risk of introducing the TWB technology. 


\section{References}

1. Marciniak, Z. and K. Kuczynski. 1967. Int. J. Mech. Sci., 9:609. 